Disponível em:

http://editora.unoesc.edu.br/index.php/race

Race, Joaçaba, v. 15, n. 1, p. 137-156, jan./abr. 2016

\title{
AVALIAĈ̃O DE MICRO E PEQUENAS EMPRESAS: A PERCEPÇÂO DO MICRO E PEQUENO EMPRESÁRIO NO ESTADO DE GOIÁS SOBRE O VALOR DA EMPRESA
}

Micro and small business evaluation: the perception of the micro and small entrepreneur in goiás state on the company value

Maira Jessika Fernandes Silva

E-mail:maira.ufg@gmail.com

Graduada em Ciências Contábeis pela Universidade Federal de Goiás; mestranda em Administração pela Universidade Federal de Goiás

Moisés Ferreira da Cunha

E-mail:mfccunha@ig.com.br

Doutor em Controladoria e Contabilidade pela Universidade de São Paulo; Mestre em Ciências Contábeis pela Universidade de Brasília; Professor Adjunto na Universidade Federal de Goiás. Endereço para correspondência: Avenida Esperança s/n, Campus Samambaia, 74690-900, Goiânia, Goiás, Brasil.

Artigo recebido em 11 de março de 2015. Aceito em 30 de setembro de 2015. 
Resumo

Nesta pesquisa teve-se como objetivo identificar a percepção dos micro e pequenos empresários no Estado de Goiás sobre o valor da empresa. Para isso, aplicou-se um questionário a 33 micro e pequenos empresários na região metropolitana de Goiânia. Para a análise dos dados, utilizouse a análise descritiva e aplicaram-se as técnicas de Análise de Correspondência (Anacor) e de Análise de Homogeneidade (Homals). Conclui-se, por meio dos dados obtidos, que os micro e pequenos empresários, de modo geral, possuem uma noção equivocada sobre o valor da empresa se contraposta aos conceitos defendidos em pesquisas. Ficou evidente a necessidade de maior empenho dos órgãos de apoio às micro e pequenas empresas em orientar os empresários sobre o valor da empresa, a fim de melhorar o seu desempenho, visando criar e maximizar valor. Palavras-chave: Micro e pequenas empresas. Avaliação de empresas. Valor.

\section{Micro and small business evaluation: the perception of the micro and small entrepreneur in goiás state on the company value}

\section{Abstract}

This research propose to identify the entrepreneur perception of firm value in micro and small companies in Goiânia, State of Goias. To this end, a survey was applied to 33 micro and small entrepreneurs in the metropolitan area of Goiânia. The data analysis use descriptive statistics, correspondence analysis techniques (Anacor) and Homogeneity Analysis (Homals).The findings show that the micro and small entrepreneurs generally do not know the firm value concept as it is explored by the finance literature. Based on this evidence, it is necessary the commitment of firms and public entities to support and guide owners of micro and small enterprises on the firm value in order to improve their performance, create and maximize value.

Keywords: Micro and small companies. Firm Valuation. Firm Value.

\section{INTRODUÇÃO}

As micro e pequenas empresas constituem a maioria das empresas existentes no Brasil e configuram-se como as maiores geradoras de renda e emprego, por isso, são de importância significativa no cenário econômico nacional. Essas empresas contribuem para a agregação de valor a produtos e serviços do País, visto que representam, aproximadamente, 27\% do Produto Interno Bruto (PIB) (SEBRAE, 2014). Entretanto, são empreendimentos com altas taxas de mortalidade, principalmente, em seus primeiros anos, pois possuem, em geral, uma má gestão.

Segundo o Sebrae (2011), as empresas da região Sudeste são as que apresentam os melhores índices de sobrevivência (76,4\%), seguidas pelas das regiões Sul 
(71,7\%), Nordeste (69,1\%), Centro-Oeste (68,3\%) e Norte (66\%). Dessa maneira, a região Centro-Oeste encontra-se em quarto lugar em índices de sobrevivência das micro e pequenas empresas. Ao se analisarem as unidades federativas da região Centro-Oeste, verificam-se os melhores índices no Distrito Federal (75\%) e em Goiás (68,0\%). Os Estados de Mato Grosso do Sul e Mato Grosso apresentam os índices de $67 \%$ e $65 \%$, respectivamente. Portanto, Goiás está em segundo lugar na referida região no índice de sobrevivência.

Alguns dos fatores que interferem para a sobrevivência das micro e pequenas empresas, de acordo com Pereira e Sousa (2009), são as falhas gerenciais, os fatores econômicos, as despesas excessivas, a falta de conhecimento de mercado, entre outros. Nesse sentido, Damodaran (1997) frisa a importância da avaliação de empresas para se verificar o impacto das decisões estratégicas, financeiras e operações na consecução do objetivo principal da empresa: a maximização do seu valor.

Diehl (2010) define valor como "[...] a capacidade de gerar ganho, riqueza econômica e benefícios de caixa futuros.” Os gestores das micro e pequenas empresas, a priori, por sua falta de capacitação, podem não entender o real significado de valor e no que isso implica para a boa gestão e continuidade de seu negócio.

Conhecer o significado do valor da empresa é importante para o gestor, pois permite gerir bem sua empresa, ter noções sobre o seu valor no mercado e saber se ela está criando e/ou destruindo sua riqueza. Saber gerenciar direcionadores de valor que maximizam benefícios futuros pode evitar, assim, a mortalidade de empresas.

Diante do exposto, surge a seguinte problemática: qual a percepção dos micro e pequenos empresários no Estado de Goiás sobre o valor da empresa?

A relevância deste estudo se dá ao considerar a importância da avaliação de empresas para identificar se a empresa está ou não criando valor e maximizando a riqueza dos proprietários, pois estas têm como objetivo a maximização do valor, que leva a um uso mais eficiente dos recursos (WESTON; COPELAND, 1992).

Os gestores de micro e pequenas empresas devem ser instigados a conhecer o valor da empresa por meio de indicadores para obter meios de criar valor e, assim, melhorar a eficiência no uso de recursos. Dessa forma, nesta pesquisa teve-se como objetivo geral identificar a percepção dos micro e pequenos empresários no Estado de Goiás sobre o valor da empresa.

Para o alcance do objetivo proposto, os seguintes objetivos específicos são necessários: identificar o perfil dos gestores das micro e pequenas empresas no Estado de Goiás e das empresas do referido Estado, além de identificar o conceito e a forma 
de estabelecimento de valor por parte dos gestores e associar o conceito percebido de valor com a forma de estabelecimento do valor.

\section{REFERENCIAL TEÓRICO}

\subsection{AS MICRO E PEQUENAS EMPRESAS}

No Brasil, as micro e pequenas empresas receberam tratamento diferenciado com a instituição da Lei Complementar n. 123/2006. Esta instituiu o regime de tributação denominado Simples Nacional, que criou uma série de facilidades em termos tributários com a unificação de tributos federais, estaduais e municipais e, também, de negócios, como, por exemplo, acesso ao crédito e preferência em licitações públicas.

A Lei considera como microempresa aquela que possui receita bruta anual de até R\$ 360.000,00 (trezentos e sessenta mil reais) e empresa de pequeno porte, aquela que possui receita bruta anual de até $\mathrm{R}$ \$ 3.600.000,00 (três milhões e seiscentos mil reais). Além da receita auferida, utiliza-se, também, o número de funcionários para a classificação do porte das micro e pequenas empresas (SEBRAE, 2014). São consideradas microempresas aquelas que possuem até nove funcionários no comércio e serviços, e até 19 funcionários na indústria e construção. As pequenas empresas têm de 10 a 49 funcionários no comércio e serviços, e de 20 a 99 funcionários na indústria e construção (SEBRAE, 2014).

As micro e pequenas empresas, geralmente, possuem estrutura familiar e constituem uma alternativa de ocupação para uma pequena parcela que tem condição de desenvolver seu próprio negócio. Também, são uma alternativa de emprego, formal ou informal, para uma grande parcela da força de trabalho excedente, em geral, com pouca qualificação e que não encontra emprego nas empresas de grande porte (IBGE, 2003).

O Instituto Brasileiro de Geografia e Estatística (IBGE) desenvolveu em 2003 um estudo no qual identificou as principais características de gestão das micro e pequenas empresas brasileiras. Entre elas estão: baixa intensidade de capital, altas taxas de natalidade e de mortalidade; forte presença de proprietários, sócios e membros da família como mão de obra ocupada nos negócios; poder decisório centralizado; estreito vínculo entre os proprietários e as empresas, não se distinguindo, principalmente em termos contábeis e financeiros, pessoa física e jurídica; registros contábeis pouco adequados; maior dificuldade de acesso ao financiamento de capital de giro, entre outras.

Similarmente, Cavalcante (2010) aponta para o pequeno empreendedor como alguém que possui a influência da baixa escolaridade, pouco contato com as novas tec- 
nologias, pequena quantidade de recursos, administração familiar e cultura de "investimentos no patrimônio", destinando seus lucros à acumulação de capital físico.

Russo (2002) enfatiza que a “[...] viabilidade de uma empresa está estruturada na figura do empresário - o empreendedor -, pois ele é o ponto central que determinará ou não o sucesso do empreendimento”, logo, o nível de conhecimento dele pode interferir em como é feita a gestão do negócio.

\subsection{O VALOR DA EMPRESA}

Para Assaf Neto (2010), “[...] a continuidade de um empreendimento somente se realiza quando suas decisões financeiras se mostrarem capazes de criar valor econômico para seus acionistas.” O mesmo autor salienta como essencial na busca de valor a organização repensar o foco de sua atividade empresarial, reestruturar seu lado operacional e estabelecer estratégias.

"Maximizar a riqueza ou o patrimônio dos acionistas significa maximizar a diferença entre o valor da empresa e o capital que os acionistas nela investiram.” (PEREZ; MARTINS, 2005). Conforme Assaf Neto (2010), a estrutura de capital de uma empresa é dividida em capital próprio, sendo este os recursos dos acionistas, e capital de terceiros, recursos obtidos de outras entidades.

Entretanto, Assaf Neto (1997) explica que “[...] o valor de uma empresa independe da forma como ela é financiada.” Isso porque “[...] sua riqueza é mensurada pela qualidade de seus investimentos, obtida pela relação de equilíbrio entre retorno e risco esperados.” Dessa forma, o mesmo autor define a taxa de atratividade da empresa como o custo de suas fontes de recursos. Esta tem seu percentual estabelecido independente da estrutura de capital apresentada, mantendo-se inalterada em todos os níveis de endividamento.

O valor de uma empresa é o valor presente de seus fluxos de caixa previstos ao longo de sua vida, medido pelo montante de recursos financeiros que será gerado no futuro pelo negócio (DAMODARAN, 2002; MARTELANC; PASIN; CAVALCANTE, 2005; TOLEDO FILHO; OLIVEIRA; SPESSATTO, 2010). O valor pode ser definido por meio de um dos modelos de avaliação de empresas (MULLER; TELO, 2003). Porém, não existe um único método para se avaliar uma empresa, o valor será determinado a fim de atingir um propósito específico, analisando-se as perspectivas dos interessados (LIMA et al., 2010).

De acordo com Perez e Martins (2005), o valor é uma medida completa para análise de desempenho da empresa, pois considera em seus cálculos a geração opera- 
cional de caixa potencial (futuro) da empresa, a taxa de atratividade dos proprietários de capital e o risco associado ao investimento.

\section{METODOLOGIA}

Para a abordagem do problema, utilizou-se pesquisa quantitativa e qualitativa. A amostra compõe-se de 33 micro e pequenas empresas da região metropolitana de Goiânia que se dispuseram a contribuir para a pesquisa e que atuam em diversos setores e atividades.

Utilizou-se para a coleta dos dados um questionário confeccionado, composto de 12 questões, e que contemplava respostas objetivas e subjetivas. O questionário foi aplicado pessoalmente a 25 proprietários de micro e pequenas empresas e a oito proprietários, via e-mail durante os meses de maio a julho de 2013.

Inicialmente, fez-se um pré-teste com três proprietários de micro e pequenas empresas e constatou-se que algumas questões subjetivas não estavam dentro da compreensão dos respondentes. Algumas questões foram adaptadas como questões objetivas, com a possibilidade de acréscimos de respostas subjetivas.

Após a aplicação dos questionários, procedeu-se a tabulação dos dados no editor de planilhas Excel. Em seguida, submeteu-se a análise dos dados com o auxílio do programa SPSS.

Para análise dos dados, realizou-se análise de estatística descritiva. Posteriormente, foram utilizadas técnicas de Análise de Correspondência (Anacor) e Análise de Homogeneidade (Homals). Essas técnicas de análise de dados investigam a relação de interdependência entre variáveis qualitativas. São, portanto, apropriadas para pesquisas com o intuito de identificar percepções dos indivíduos, pois permitem a criação de mapas perceptuais que demonstram um exame visual do comportamento dos dados categóricos (FAVERO et al., 2009). A Anacor estuda o comportamento de apenas duas variáveis, enquanto a Homals estuda diversas variáveis simultaneamente (FAVERO et al., 2009). Para utilizar a Anacor e a Homals, deve-se aplicar o teste Qui-quadrado e rejeitar a hipótese nula. Esse teste possui a hipótese nula de não associação entre as variáveis, portanto, para a aplicação das referidas técnicas, o teste deve ser rejeitado, indicando a relação de dependência entre as variáveis (FAVERO et al., 2009). Na aplicação do teste Qui-quadrado, a hipótese nula foi rejeitada a um nível de significância de 5\%. 


\section{RESULTADOS}

\subsection{ANÁLISE DESCRITIVA}

Nesta análise, as questões aplicadas foram divididas por assunto. Primeiro apresentam-se a escolaridade dos proprietários e o perfil das empresas. Em segundo lugar são apresentadas as questões sobre o controle financeiro da empresa e o controle do fluxo de caixa. Em terceiro lugar analisam-se as questões sobre valor e lucratividade. Por fim, são tratadas as questões sobre estrutura de capital e risco do negócio.

Tabela 1 - Escolaridade dos proprietários e caracterização das empresas

\begin{tabular}{|c|c|c|c|}
\hline & & Frequência & $\%$ \\
\hline \multirow[t]{6}{*}{ Escolaridade } & Fundamental completo & 2 & 6,1 \\
\hline & Médio incompleto & 4 & 12,1 \\
\hline & Médio completo & 15 & 45,5 \\
\hline & Superior incompleto & 4 & 12,1 \\
\hline & Superior completo & 5 & 15,2 \\
\hline & Pós-graduação & 3 & 9,1 \\
\hline \multirow[t]{3}{*}{ Setor } & Comércio & 20 & 60,6 \\
\hline & Serviço & 8 & 24,2 \\
\hline & Misto & 5 & 15,2 \\
\hline \multirow[t]{4}{*}{ Tempo de Mercado } & Mais de 10 anos & 15 & 45,5 \\
\hline & 5-10 anos & 8 & 24,2 \\
\hline & $1-5$ anos & 9 & 27,3 \\
\hline & 1 ano ou menos & 1 & 3,0 \\
\hline \multirow[t]{2}{*}{ Porte } & Micro & 20 & 60,6 \\
\hline & Pequena & 13 & 39,4 \\
\hline Total & & 33 & 100,0 \\
\hline
\end{tabular}

Fonte: os autores.

Conforme pode ser observado na Tabela 1, entre os respondentes da pesquisa, a maioria possui o ensino médio (45,5\%), e os que possuem o ensino superior completo representam 15,2\%. Quanto às características das empresas em que estes são proprietários, o comércio é o setor de atuação de 60,6\%, o de serviços, 24,2\%, e $15,2 \%$ atuam em setor misto. O tempo de mercado da maioria das empresas é de mais de 10 anos (45,5\%), seguido por 1 a 5 anos (27,3\%) e 5 a 10 anos (24,2\%). Portanto, já atuam há um tempo no mercado. Em relação ao porte, 60,6\% são microempresas e 39,4\% são pequenas empresas. 
Tabela 2 - Questões sobre o controle financeiro da empresa

\begin{tabular}{|c|c|c|c|c|c|c|c|c|}
\hline \multicolumn{3}{|c|}{$\begin{array}{l}\text { Você tem um retorno mínimo } \\
\text { requerido pelo seu investi- } \\
\text { mento na empresa? }\end{array}$} & \multicolumn{2}{|c|}{$\begin{array}{l}\text { Você tem uma ges- } \\
\text { tão (controle) sobre } \\
\text { o fluxo de caixa da } \\
\text { empresa? }\end{array}$} & \multicolumn{2}{|c|}{$\begin{array}{l}\text { A empresa planeja } \\
\text { sua posição finan- } \\
\text { ceira no futuro? }\end{array}$} & \multicolumn{2}{|c|}{$\begin{array}{l}\text { Sabe se sua empresa } \\
\text { cria valor, ou seja, } \\
\text { se ela vale mais no } \\
\text { mercado do que } \\
\text { quando você a } \\
\text { constituiu? }\end{array}$} \\
\hline & Frequência & $\%$ & Frequência & $\%$ & Frequência & $\%$ & Frequência & $\%$ \\
\hline SIM & 24 & 72,7 & 22 & 67 & 23 & 70 & 29 & 88 \\
\hline NÃO & 9 & 27,3 & 11 & 33 & 10 & 30 & 4 & 12 \\
\hline Total & 33 & 100 & 33 & 100 & 33 & 100 & 33 & 100 \\
\hline
\end{tabular}

Fonte: os autores.

Na Tabela 2, encontram-se as questões sobre o controle financeiro da empresa. Pode-se inferir que, entre os respondentes, a maioria (72,7\%) possui um retorno mínimo requerido pelo investimento na empresa. Para os que afirmaram isso, perguntou-se sobre o percentual desse retorno. A média foi de 25,32\%.

Similarmente ao exposto anteriormente, 70\% planejam sua posição no futuro, e $88 \%$ afirmaram saber que a empresa cria valor. Ainda, 67\% afirmaram possuir uma gestão sobre o fluxo de caixa da empresa e, para estes, perguntou-se como é realizado o controle. Sendo as respostas subjetivas, estas se encontram na Tabela 3. Logo, os micro e pequenos empresários possuem perspectivas em relação ao investimento feito na empresa.

Tabela 3 - Controle do fluxo de caixa da empresa

\begin{tabular}{lrr}
\hline Como é feito o controle de fluxo de caixa da empresa? & & \\
\hline & Frequência & $\%$ \\
\hline Contador & 5 & 23 \\
Entradas e saídas & 11 & 50 \\
Programa interno & 2 & 9 \\
Não responderam & 4 & 18 \\
Total & 22 & 100,0 \\
\hline
\end{tabular}

Fonte: os autores.

Nota-se pela Tabela 3, que 50\% dos empresários realizam o controle do fluxo de caixa por meio da comparação das entradas e saídas da empresa, em geral, por anotações à mão ou software de planilhas de cálculo. Assim, infere-se que o empresário mantém pessoalmente um controle razoável do fluxo de caixa da empresa. Já 23\% dos 
respondentes o controlam pelo contador, e 9\% possuem programa interno para esse controle. Esse último resultado mostra o baixo uso de programas de apoio à decisão.

Tabela 4 - Questões sobre valor e lucratividade

\begin{tabular}{|c|c|c|}
\hline \multicolumn{3}{|l|}{ Para você, qual é o conceito de valor? } \\
\hline & Frequência & $\%$ \\
\hline Custo do investimento & 5 & 15,2 \\
\hline Preço percebido pelo mercado e disposto a pagar & 23 & 69,7 \\
\hline Quantia que posso obter usando o bem & 2 & 6,1 \\
\hline Quantia que consigo ao trocar o bem & 1 & 3,0 \\
\hline Outro & 2 & 6,1 \\
\hline Total & 33 & 100,0 \\
\hline \multicolumn{3}{|l|}{ Como você estabelece o valor da sua empresa? } \\
\hline & Frequência & $\%$ \\
\hline Valor presente dos fluxos de caixa futuros esperados & 8 & 24,2 \\
\hline Valor investido ao constituí-la & 12 & 36,4 \\
\hline Valor similar ao de uma empresa concorrente & 6 & 18,2 \\
\hline Outro & 7 & 21,2 \\
\hline Total & 33 & 100,0 \\
\hline \multicolumn{3}{|l|}{ De que modo verifica que o seu negócio é lucrativo? } \\
\hline & Frequência & $\%$ \\
\hline Comparando as entradas de dinheiro com as saídas & 20 & 60,6 \\
\hline O que excede ao retorno requerido & 2 & 6,1 \\
\hline Relação entre o lucro contábil e o investimento feito & 9 & 27,3 \\
\hline Relação entre a sobra no caixa e o investimento feito & 1 & 3,0 \\
\hline Outro & 1 & 3,0 \\
\hline Total & 33 & 100,0 \\
\hline
\end{tabular}

Fonte: os autores.

Na Tabela 4, encontram-se as perguntas e respostas sobre valor e lucratividade. Percebe-se entre os respondentes o conceito de valor - "preço percebido pelo mercado e disposto a pagar” - sendo a opção de 69,7\%. De acordo com Fama (1970), “[...] os preços refletem plenamente toda a informação disponível”, e esta é influenciada pela sua disponibilidade e pelos custos de transação e interfere diretamente na eficiência do mercado (FORTI et al., 2009). Portanto, tal conceito pode ser utilizado ao se considerar que o mercado é eficiente. Entretanto, pesquisas (SALLES, 1991; SCHIEHLL, 1996; GALDÃO; FAMÁ, 1998; BUENO; BRAGA; ALMEIDA, 2000; 
PEROBELLI; NESS JÚNIOR, 2000; CERETTA, 2001; PROCIANOY; ANTUNES, 2001; VIEIRA; PROCIANOY, 2001; GARCIA, 2003; CAMARGOS; BARBOSA, 2003) mostram que em mercados emergentes, como o Brasil, o mercado não é tido como totalmente eficiente, o que denota que o valor de mercado reflete parcialmente as informações disponíveis.

Verifica-se, ainda, na Tabela 4, no que diz respeito ao modo de o empresário estabelecer valor para a sua empresa, um equilíbrio entre as respostas. Ao se considerar, porém, a resposta “valor investido ao constituí-la”, compreende-se que tal concepção é equivocada, pois, assim, o valor da empresa, para os entrevistados, não sofre alterações com o passar do tempo, ou seja, avaliam suas empresas pelo valor de custo, resultado que vai de encontro à resposta da maioria sobre “Qual é o conceito de valor”, na qual $24,2 \%$ responderam que estabelecem o valor pelo fluxo de caixa futuro, e 18,2\%, pelo valor similar de outra empresa concorrente (múltiplo). Nesse sentido, admite-se o conceito de valor com a seguinte formulação: o valor de uma empresa é o valor presente de seus fluxos de caixa futuros (DAMODARAN, 2002; MARTELANC; PASIN; CAVALCANTE, 2005; TOLEDO FILHO; OLIVEIRA; ESPESSATTO, 2010).

Quanto à lucratividade, esta é verificada por 60,6\% dos respondentes comparando-se as entradas de dinheiro com as saídas, ou seja, pelo regime de caixa no qual se reconhecem as despesas e as receitas somente quando há entrada ou saída de caixa. Contudo, Augustini (1999) explica que todo o processo de apuração de resultado contábil e de posições patrimoniais é realizado pelo regime de competência, logo, o reconhecimento deveria ser feito de acordo com os fatos geradores.

Com o intuito de identificar a compreensão dos micro e pequenos empresários a respeito da composição da estrutura de capital da empresa, perguntou-se o percentual destinado a recursos próprios e a recursos de terceiros. Considerou-se “certo” a soma dos percentuais $100 \%$ e "errado" as somas diferentes de $100 \%$. Neste caso, $82 \%$ acertaram e 18\% erraram, indicando que há entre o micro e o pequeno empresário discernimento a respeito da composição da estrutura de capital.

No que se refere ao risco do negócio, questionou-se a classificação determinada pelo empresário em uma escala de 0 a 100\%, supondo a primeira para menor risco e a segunda para maior risco. Desse modo, obteve-se uma média de risco de 26\%, o que, pela escala, pode-se considerar que na percepção dos micro e pequenos empresários os seus negócios possuem um baixo risco. Assaf Neto (2007) classifica o nível de risco em baixo, médio e alto, de acordo com a estrutura financeira da empresa, entretanto, para se utilizar tal classificação, faz-se necessário outro estudo. 


\subsection{ANÁLISE DE INTERDEPENDÊNCIA}

Para analisar as relações de interdependência entre as variáveis qualitativas com as técnicas de Análise de Correspondência (Anacor) e Análise de Homogeneidade (Homals), aplicou-se o teste Qui-quadrado a um nível de significância de 5\%.

Tabela 5 - Teste Qui-quadrado

\begin{tabular}{llll}
\hline & Associações aceitas & Significância & Hipótese \\
\hline Anacor & conceito de valor - verifica lucratividade & 0,002 & rejeita \\
\hline \multirow{2}{*}{ Homals } & estabelece valor - gestão de fluxo de caixa & 0,038 & rejeita \\
& estabelece valor - tempo de mercado & 0,039 & rejeita \\
& estabelece valor - setor & 0,038 & rejeita \\
\hline
\end{tabular}

Fonte: os autores.

Entre as possíveis associações, somente as que constam na Tabela 5 rejeitaram a hipótese nula do teste Qui-quadrado de independência das variáveis, com as quais foi possível a aplicação das técnicas citadas.

Figura 1 - Mapa Perceptual - Associação entre conceito de valor e verificação de lucratividade

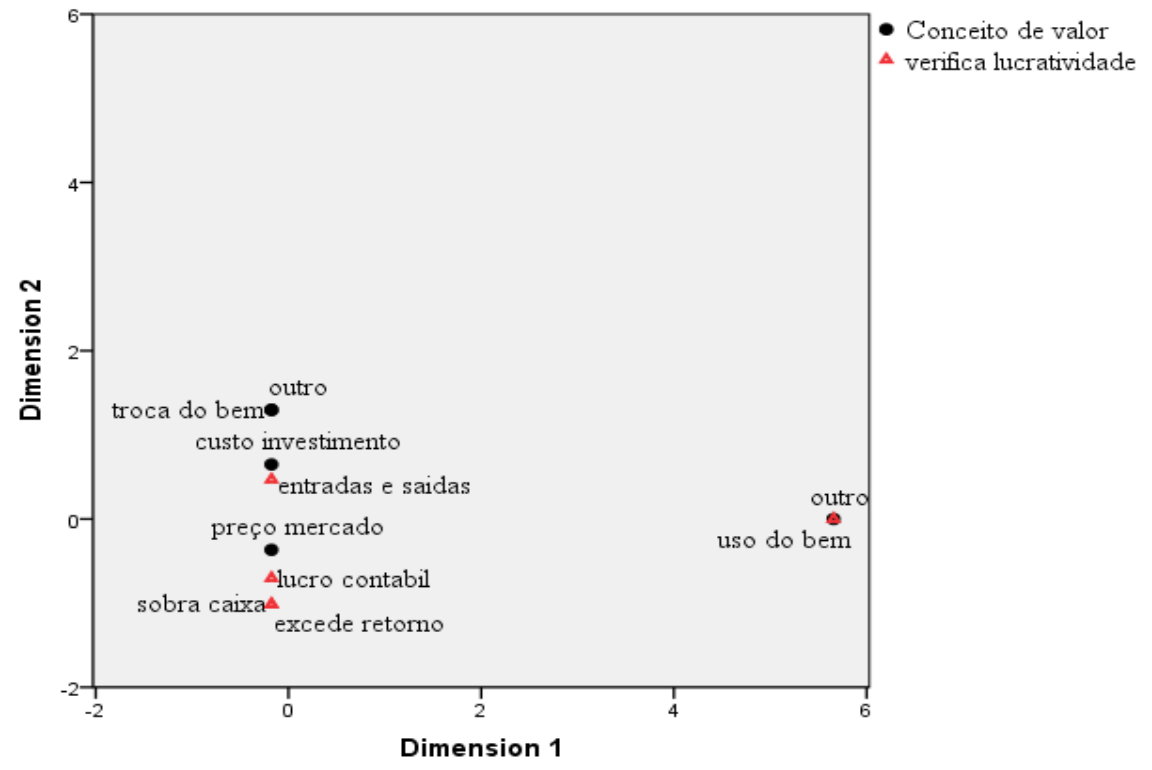

Fonte: os autores. 
Na Anacor, associou-se o conceito de valor do empresário com o seu modo de verificar a lucratividade. Constata-se, por meio do mapa perceptual da Figura 1, associação entre o conceito “custo do investimento” e a verificação de lucratividade comparando-se às “entradas e saídas”. Conforme já exposto, o conceito é equivocado, pois avaliam a empresa pelo valor de custo, e tal verificação é feita pelo regime de caixa, quando deveria ser feita pelo regime de competência. O conceito de valor “preço percebido pelo mercado e disposto a pagar” associa-se com a verificação de lucratividade “relação entre o lucro da contabilidade e o investimento feito". Portanto, infere-se que o conceito de valor entendido pelo empresário pode interferir em como este verifica se o negócio é lucrativo.

Figura 2 - Mapa Perceptual - Associação entre valor, fluxo de caixa, setor e tempo de mercado

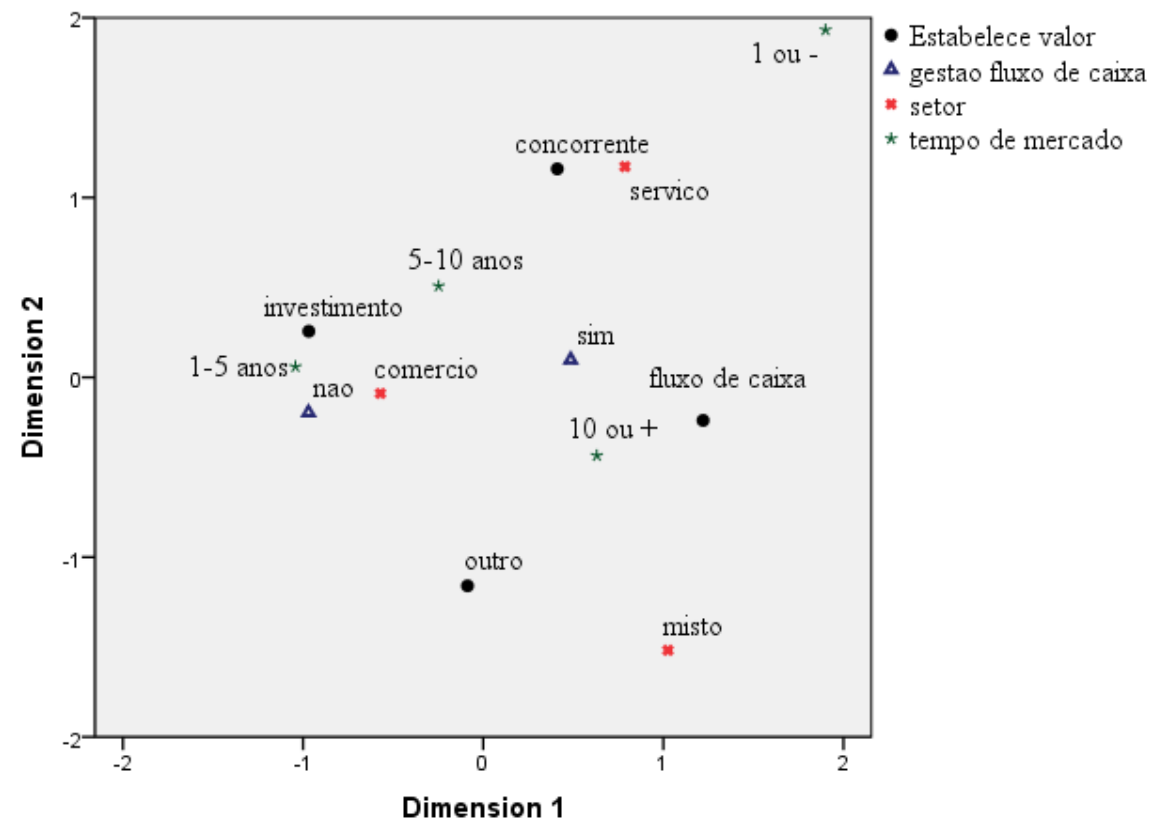

Variable Principal Normalization.

Fonte: os autores.

Na Homals, associou-se o modo como o empresário estabelece valor com o setor, o tempo de mercado e a afirmação de existência ou não de gestão de fluxo de caixa. Percebe-se, por meio do mapa da Figura 2, que o empresário que possui 10 anos ou mais de tempo de mercado possui gestão de fluxo de caixa e estabelece o valor da empresa por meio do valor presente de seus fluxos de caixa futuros (DAMODARAN, 
2002; MARTELANC; PASIN; CAVALCANTE, 2005; TOLEDO FILHO; OLIVEIRA; ESPESSATTO, 2010).

Constata-se, ainda na Figura 2, que o empresário que possui de 1 a 5 anos de mercado não possui gestão de fluxo de caixa e estabelece o valor por meio do custo do investimento, tendo como setor mais próximo o do comércio. Desse modo, pode-se compreender que o tempo de mercado do empresário e a gestão do fluxo de caixa influenciam sua concepção de valor.

\section{CONCLUSÃO}

Nesta pesquisa teve-se como objetivo identificar a percepção dos micro e pequenos empresários no Estado de Goiás sobre o valor da empresa. Por meio dos dados obtidos, verificou-se para a maioria dos micro e pequenos empresários o conceito de valor "preço percebido pelo mercado e disposto a pagar". Tal resultado vai de encontro ao conceito defendido em pesquisas de que o valor da empresa é o valor presente de seus fluxos de caixa futuros (DAMODARAN, 2002; MARTELANC; PASIN; CAVALCANTE, 2005; TOLEDO FILHO; OLIVEIRA; ESPESSATTO, 2010). É importante ressaltar a relação do tempo de mercado e o controle de fluxo de caixa com tal conceito.

A análise possibilitou verificar a percepção dos micro e pequenos empresários em relação a alguns conceitos que envolvem o valor da empresa: retorno requerido, criação de valor, estrutura de capital, fluxo de caixa e lucratividade. Quanto à estrutura de capital, constatou-se que a maioria dos respondentes possui discernimento sobre a composição da estrutura de capital. Foi possível identificar, quanto aos controles financeiros da empresa, perspectivas em relação ao investimento feito na empresa.

Portanto, conclui-se que, embora os micro e pequenos empresários possuam perspectivas em relação ao negócio, a percepção destes sobre o valor da empresa precisa ser desenvolvida. Nesse sentido, nota-se a necessidade de órgãos de apoio às micro e pequenas empresas, como o Serviço Brasileiro de Apoio às Micro e Pequenas Empresas (Sebrae), por exemplo, de investir em cursos e palestras explicando tais conceitos.

Esta pesquisa teve como limitação a disposição e a disponibilidade dos micro e pequenos empresários em responder ao questionário, o que interferiu no tamanho da amostra. Considerando-se esse fato, a amostra foi composta de apenas 33 respondentes, de modo que não se pode generalizar os resultados. Outra limitação se refere à possível falta de entendimento de alguns empresários em relação aos questionamentos feitos. 
Assim, sugere-se para pesquisas futuras a ampliação da amostra de pesquisa para acrescentar os resultados ora apresentados. Outra sugestão seria classificar o risco do negócio das micro e pequenas empresas.

\section{REFERÊNCIAS}

ASSAF NETO, A. A dinâmica das decisões financeiras. Caderno de estudos $\mathbf{n}^{\mathbf{0}} \mathbf{1 6}$, São Paulo, jul./dez. 1997. Disponível em: <http://www.revistas.usp.br/cest/article/ view/5615/7145>. Acesso em: 25 jun. 2013.

ASSAF NETO, A. Bases conceituais do processo de avaliação de empresas. 2007. Disponível em: <http://www.institutoassaf.com.br/downloads/ARTIGO_SITE_INSTITUTO_ASSAF_II.pdf $>$. Acesso em: 12 jul. 2013.

ASSAF NETO, A. Finanças Corporativas e Valor. 3. ed. São Paulo: Atlas, 2010.

AUGUSTINI, C. A. D. Capital de Giro. São Paulo: Atlas, 1999.

BRASIL. Lei Complementar n. 123, de 14 de dezembro de 2006. Institui o Estatuto Nacional da Microempresa e Empresa de Pequeno Porte. Disponível em: <http:// www.receita.fazenda.gov.br/Legislacao/LeisComplementares/2006/leicp123.htm>. Acesso em: 26 dez. 2012.

BUENO, A. F.; BRAGA, R. F. R.; ALMEIDA, R. J. Pesquisa sobre a eficiência informacional no mercado brasileiro nos casos de fusões e aquisições. In: ENCONTRO NACIONAL DA ASSOCIAÇÃO NACIONAL DOS PROGRAMAS DE PÓS-GRADUAÇÃO EM ADMINISTRAÇÃO, 24., 2000, Florianópolis. Anais... Florianópolis: ANPAD, 2000.

CAMARGOS, M. A. de; BARBOSA, F. D. Teoria e evidência da eficiência informacional do mercado de capitais brasileiro. Caderno de Pesquisas em Administração, São Paulo, v. 10, n. 1, jan./mar. 2003.

CAVALCANTE, E. M. C. O planejamento de micro e pequenas empresas comerciais por meio da atuação da controladoria. 2010. 60 p. Trabalho de Conclusão de Curso (Graduação em Ciências Contábeis)-Faculdade Lourenço Filho, Fortaleza, 2010.

CERETTA, P. S. Comportamento das variações de preço nos mercados de ações da América Latina. In: ENCONTRO NACIONAL DA ASSOCIAÇÃO NACIONAL DOS PROGRAMAS DE PÓS-GRADUAÇÃO EM ADMINISTRAÇÃO, 25., 2001, Campinas. Anais... Campinas: ANPAD, 2001. 
CORRÊA, A. C. C.; MATIAS, A. B.; VICENTE, E. F. R. Balanço perguntado: uma metodologia de obtenção de demonstrativos financeiros de micro e pequenas empresas. In: SEMINÁRIO DE ADMINISTRAÇÃO FEA-USP, 9., 2006, São Paulo. Anais... São Paulo, 2006. Disponível em: <http://www.ead.fea.usp.br/Semead/9semead/resultado_semead/trabalhosPDF/52.pdf>. Acesso em: 22 fev. 2012

CUNHA, M. A. O perfil da administração financeira das pequenas e médias empresas. FGV SB, 2002. Disponível em: <http://bibliotecadigital.fgv.br/mwg-internal/ de5fs23hu73ds/progress?id=+vXH7euyrJ>. Acesso em: 24 out. 2012.

DAMODARAN, A. A face oculta da avaliação. São Paulo: Makron Books, 2002.

DAMODARAN, A. Avaliação de investimentos: ferramentas e técnicas para determinação do valor de qualquer ativo. Rio de Janeiro: Qualitymark, 1997.

DIEHL, T. M. Principais métodos de avaliação de empresas: vantagens e desvantagens. Porto Alegre, 2010. 25 p. Trabalho de Conclusão de Curso (Graduação em Ciências Contábeis)-Universidade Federal do Rio Grande do Sul, Porto Alegre, 2010.

FAMA, E. F. Efficient capital markets: a review of theory and empirical work. The Journal of Finance, Cambridge, v. 25, p. 383-417, May 1970.

FÁVERO, L. P. et al. Análise de dados: modelagem multivariada para tomada de decisões. Rio de Janeiro: Elsevier, 2009.

FORTI, C. A. B. et al. Hipótese da eficiência de mercado: um estudo exploratório no mercado de capitais brasileiro. 2009. Disponível em: <http://www.ead.fea.usp.br/ semead/12semead/resultado/trabalhosPDF/947.pdf>. Acesso em: 17 jul. 2013.

GALDÃO, A.; FAMÁ, R. Avaliação da eficiência na precificação de ações negociadas no Brasil, por teste de volatilidade. Revista de Administração, São Paulo, v. 33, n. 2, p. 60-68, abr./jun. 1998.

GARCIA, G. M. Eficiência do mercado implícito de câmbio a termo no Brasil. 2003. 51 p. Dissertação (Mestrado em Economia)-Universidade de São Paulo, São Paulo, 2003. 
IBGE. As micro e pequenas empresas comerciais e de serviços no Brasil. 2001. Disponível em: <http:/www.ibge.gov.br/home/estatistica/economia/microempresa/ microempresa2001.pdf>. Acesso em: 27 jul. 2012.

IBGE. Cadastro Central de Empresas. 2003. Disponível em: <http:// www.sidra. ibge.gov.br>. Acesso em: 27 jul. 2012.

KASSAI, J.; KASSAI, S. Balanço perguntado: uma técnica para elaborar relatórios contábeis de pequenas empresas. In: CONGRESSO BRASILEIRO DE CUSTOS, 11., 2004, Porto Seguro. Anais... Porto Seguro, 2004.

LIMA, M. V. A. et al. Avaliação de micro e pequenas empresas utilizando a metodologia multicritério e o método do fluxo de caixa descontado. Revista de Ciências da Administração - UFSC, v. 12, n. 26, p. 48-71, jan./abr. 2010. Disponível em: <http://stat.contabilidade.periodicos.ufsc.br/index.php/adm/article/view/14079>. Acesso em: 20 fev. 2012.

MARTELANC, R.; PASIN, R.; CAVALCANTE, F. Avaliação de empresas: um guia para fusões e aquisições e gestão de valor. São Paulo: Pearson Prentice Hall, 2005.

MATIAS, A. B.; LOPES JÚNIOR, F. Administração financeira nas empresas de pequeno porte. São Paulo: Manole, 2002.

MULLER, A. N.; TELO, A. R. Modelos de avaliação de empresas. Revista FAE, Curitiba, v. 6, n. 2, p. 97-112, maio/dez. 2003.

PEREIRA, R. C. M.; SOUSA, P. A. Fatores de mortalidade de micro e pequenas empresas: um estudo sobre o setor de serviços. In: SIMPÓSIO DE EXCELÊNCIA EM GESTÃO E TECNOLOGIA, 2009. Anais... 2009. Disponível em: <http://www. aedb.br/seget/artigos09/195_Mortalidade_nas_MPEs.pdf>. Acesso em: 16 abr. 2013.

PEREZ, M. M.; MARTINS, R. C. S. Decifrando a geração de valor ao acionista. In: ENCONTRO NACIONAL DA ASSOCIAÇÃO NACIONAL DOS PROGRAMAS DE PÓS-GRADUAÇÃO EM ADMINISTRAÇÃO, 29., 2005, Brasília. Anais... Brasília: ANPAD, 2005. Disponível: <http://www.anpad.org.br/diversos/trabalhos/ EnANPAD/enanpad_2005/FIC/FICD2817.pdf>. Acesso em: 24 jul. 2013. 
PEROBELLI, F. F. C.; NESS JÚNIOR, W. Reações do mercado acionário a variações inesperadas nos lucros das empresas: um estudo sobre a eficiência informacional no mercado brasileiro. In: ENCONTRO NACIONAL DA ASSOCIAÇÃO NACIONAL DOS PROGRAMAS DE PÓS-GRADUAÇÃO EM ADMINISTRAÇÃO, 24., 2000, Florianópolis. Anais... Florianópolis: ANPAD, 2000.

PROCIANOY, J. L.; ANTUNES, M. A. Os efeitos das decisões de investimento das firmas sobre os preços de suas ações no mercado de capitais. In: ENCONTRO NACIONAL DA ASSOCIAÇÃO NACIONAL DOS PROGRAMAS DE PÓS-GRADUAÇÃO EM ADMINISTRAÇÃO , 25., 2001, Campinas. Anais... Campinas: ANPAD, 2001.

RUSSO, D. R. Problemas das micro e pequenas empresas - Um estudo junto aos clientes do Balcão Sebrae - Sede/Porto Alegre. 2002. 116 p. Dissertação (Mestrado em Administração)-Universidade Federal do Rio Grande do Sul, Porto Alegre, 2002.

SALLES, A. A. Eficiência informacional do mercado futuro do Ibovespa. In: ENCONTRO NACIONAL DA ASSOCIAÇÃO NACIONAL DOS PROGRAMAS DE PÓS-GRADUAÇÃO EM ADMINISTRAÇÃO , 15., 1991, Salvador. Anais... Salvador: ANPAD, 1991.

SCHIEHLL, E. O efeito da divulgação das demonstrações contábeis no mercado de capitais brasileiro: um estudo sobre a variação no preço das ações. In: ENCONTRO NACIONAL DA ASSOCIAÇÃO NACIONAL DOS PROGRAMAS DE PÓS-GRADUAÇÃO EM ADMINISTRAÇÃO , 20., 1996, Angra dos Reis. Anais... Angra dos Reis: ANPAD, 1996.

\section{SEBRAE. Participação das Micro e Pequenas Empresas na Economia Brasile-} ira. 2014. Disponível em: <http://www.sebrae.com.br/Sebrae/Portal\%20Sebrae/ Estudos\%20e\%20Pesquisas/Participacao\%20das\%20micro\%20e\%20pequenas\%20 empresas.pdf>. Acesso em: 03 set. 2015.

SEBRAE. Taxa de sobrevivência das empresas no Brasil. 2011. Disponível em: <http://www.biblioteca.sebrae.com.br/bds/BDS.nsf/45465B1C66A6772D832579300051816C/\$File/NT00046582.pdf >. Acesso em: 27 jul. 2012.

TOLEDO FILHO, J. R.; OLIVEIRA, E. L.; SPESSATTO, G. Fluxo de caixa como instrumento de controle gerencial para tomada de decisão: um estudo realizado em microempresas. Revista de Contabilidade do Mestrado em Ciências Contábeis da UERJ, Rio de Janeiro, v. 15, n. 2, p. 75-88, maio/ago. 2010. 
VIEIRA, K. M.; PROCIANOY, J. L. Reação dos investidores a bonificações: um estudo em países da América Latina. In: ENCONTRO NACIONAL DA ASSOCIAÇÃO NACIONAL DOS PROGRAMAS DE PÓS-GRADUAÇÃO EM ADMINISTRAÇÃO, 25., Anais... Campinas: ANPAD, 2001.

WESTON, J. F.; COPELAND, T. E. Managerial Finance. 9. ed. Florida: Dryden Press, 1992.

Como citar este artigo:

\section{ABNT:}

SILVA, Maira Jessika Fernandes; CUNHA, Moisés Ferreira da. Avaliação de micro e pequenas empresas: a percepção do micro e pequeno empresário no estado de Goiás sobre o valor da empresa. RACE: Revista de Administração, Contabilidade e Economia, Joaçaba: Ed. Unoesc, v. 15, n. 1, p. 137-156, jan./abr. 2016. Disponível em: <http://editora.unoesc.edu.br/index.php/race>. Acesso em: dia/mês/ano.

\section{APA:}

Silva, M. J. F., \& Cunha, M. F. da. (2016). Avaliação de micro e pequenas empresas: a percepção do micro e pequeno empresário no estado de Goiás sobre o valor da empresa. RACE: Revista de Administração, Contabilidade e Economia, 15(1), 137-156. Recuperado em dia/mês/ano, de http://editora.unoesc.edu.br/index.php/race 


\section{Apêndice A - Questionário da pesquisa}

1. Qual o cargo do respondente da pesquisa?

( ) Sócio(a)/ proprietário(a)/ dono(a)/ titular/ administrador.

( ) Gerente/ auxiliar administrativo/ assistente administrativo.

( ) Funcionário(a)/ vendedor(a)/ balconista

2. Qual o grau de escolaridade do respondente da pesquisa?

( ) Ensino fundamental incompleto ( ) Ensino fundamental completo

( ) Ensino médio incompleto ( ) Ensino médio completo

( ) Ensino superior incompleto ( ) Ensino superior completo

( ) Pós-graduação completa ou incompleta

3. Qual o ramo de atuação da empresa?

( ) Comércio ( ) Serviço ( ) Indústria ( ) Outro

4. Qual o tempo de mercado?

( ) Menos de 1 ano ( ) De 1 a 5 anos ( ) De 5 a 10 anos ( ) Mais de 10 anos

5. Qual o porte da empresa?

( ) Micro ( ) Pequena ( ) Média ( ) Grande

6. Para você, qual é o conceito de valor?

( ) Custo do investimento

( ) Preço percebido pelo mercado e disposto a pagar

( ) Quantia que posso obter usando o bem

( ) Quantia que consigo ao trocar o bem

( ) Outro

7. Você tem um retorno mínimo requerido pelo seu investimento na empresa?

( ) Sim ( ) Não

Se sim, de quanto? $\%$

8. Como você estabelece o valor da sua empresa?

( ) Valor presente dos fluxos de caixa futuros esperados

( ) Valor que investi ao constituí-la

( ) O valor de minha empresa é similar (parecido) ao valor de uma empresa concorrente

( ) Outro 
9. De que modo verifica que o seu negócio é lucrativo?

( ) Comparando as entradas de dinheiro com as saídas

( ) Relação entre o dinheiro que sobrou no caixa e o investimento feito

( ) Relação entre o lucro que a contabilidade me informou e o investimento feito

( ) $\mathrm{O}$ que excede ao meu retorno requerido (desejado)

( ) Outro

10. Sabe se sua empresa cria valor, ou seja, se ela vale mais no mercado do que quando você a constituiu?

( ) Sim ( ) Não

11. Você tem uma gestão (controle) sobre o fluxo de caixa da empresa?

( ) Sim ( ) Não

Se sim, como é feito esse controle?

12. Qual a maior parte do financiamento de sua empresa? Seu capital (dinheiro próprio) ou empréstimos de terceiros (dívida)?

Capital próprio (seu dinheiro) $\%$

Capital de terceiros (dívida) $\%$

13. A empresa planeja sua posição financeira no futuro?

( ) Sim ( ) Não

14. Como você classificaria o risco atual de seu negócio? (0\% para menor risco, 100\% para maior ris$\mathrm{co})$. 